\title{
Can You Hear Me Now?: How Communication Technology Affects Protest and Repression ${ }^{\star}$
}

\author{
Darin Christensen ${ }^{\dagger}$ and Francisco Garfias ${ }^{\ddagger}$
}

January 15, 2018

\begin{abstract}
Commentators covering recent social movements, such as the Arab Spring, commonly claim that cell phones enable protests. Yet, existing empirical work does not conclusively support this contention: some studies find that these technologies actually reduce collective action; many others struggle to overcome the selection problems that dog observational research. We propose two mechanisms through which cell phones affect protests: first, by enabling communication among would-be protesters, cell phones lower coordination costs; and second, these technologies broadcast information about whether a protest is repressed. Knowing that a larger audience now witnesses and may be angered by repression, governments refrain from squashing demonstrations, further lowering the cost of protesting. We evaluate these mechanisms using highresolution global data on the expansion of cell phone coverage and incidence of protest from 2007-2014. Our difference-in-differences estimates indicate that cell phone coverage increases the probability of protest by over half the mean. Consistent with our second mechanism, we also find that gaining coverage has a larger effect when it connects a locality to a large proportion of other citizens.
\end{abstract}

${ }^{*}$ We are grateful to Julie Sweetkind-Singer for her help procuring the data on cell phone coverage, and Avidit Acharya, Eli Berman, Nick Eubank, James Fearon, Jens Hainmueller, David Laitin, José Merino, Ramya Parthasarathy, Ken Scheve, and participants at the 2015 MPSA conference, 2015 Berkeley-Stanford Political Economy Workshop, and 2015 APSA conference for their thoughtful feedback on earlier drafts. We thank the QJPS editors and two anonymous referees for their careful and constructive reviews.

${ }^{\dagger}$ Assistant Professor of Public Policy, UCLA. e: darinc@luskin.ucla.edu

${ }^{\ddagger}$ Assistant Professor of Political Science, UCSD. e: fgarfias@ucsd.edu 
Media coverage of recent social movements - the Arab Spring, the Green Movement in Iran, and the Occupy movements in the U.S. and Turkey — frequently asserts that communication technologies facilitate protests. Headlines proclaim that cell phones and social media "fuel protests in Iran, Bahrain, and Yemen" (ABC News 2011), "give Wall Street Protests a Global Reach" (Preston 2011), and are “key to [Turkey’s] 'Occupy Gezi’ protests” (Dorsey 2013).

Yet, social movements predate the Internet, cell phones, or even broadcast media. Fischer (2013) recounts widespread protests during 1968 (e.g., in Belgrade, Bonn, Chicago, Paris, Prague, Warsaw and many other cities); the diffusion of sit-ins and demonstrations during the U.S. civil rights movement; and the revolutions of 1848, which affected many European and even some Latin American countries. He cites a recent comparison of the Arab Spring and the revolutions of 1848 in which Weyland $(2012,919)$ observes that "the 1848 revolutions spread just as fast as the MENA protests, long before 24/7 TV news, Twitter, and Facebook." These historical events suggest that our contemporary fascination with mobile phones and social media may overestimate the importance of these technologies. Fischer concludes, "we do not know how they have made mobilization and diffusion different than in the television era, or in the telegraph era for that matter."

We address this ongoing debate about whether and why these new technologies have a causal effect on protest activity. Our theory illustrates the direct and indirect effects of cell phone access on protest. First, cell phones have a direct effect by reducing coordination costs for would-be demonstrators. Cell phones enable individuals to share information about where or when a protest will occur (Little 2015). Second, the expansion of cell phone networks has an indirect effect that also increases the likelihood of protest. Where a large proportion of citizens have cell phones, the government fears that the mass public will learn of, and may be enraged by, repression. Fearing that repression could spark escalation, the government may soften its response. As the expected level of repression falls, protesting becomes less costly and, thus, more likely. In the recent pro-democracy protests in Hong Kong, police were caught on video beating an activist. Leung (2014) writes that "For the neutrals, this episode could well be the tipping point...[A]fter such a brutal beating - which 
we know happens all the time behind closed doors ... but just never in public - it's become harder for many to just sit on the fence. Indeed, more people are back out on the streets... and angrier than ever." By documenting and digitally sharing evidence of police brutality, protesters translated outrage over repression into additional support.

We provide evidence for these mechanisms using a quasi-experimental, difference-in-differences design that exploits high-resolution global data on the expansion of cell phone networks and the incidence of protest from 2007-2014. In short, we find (1) that gaining coverage increases the probability of protest by over half the mean, (2) that this effect is larger where a greater share of a country's population is connected to the network, and (3) that gaining coverage reduces the likelihood of repression. The last two findings suggest that cell phones not only enable coordination (the direct effect), but also temper the government's response by raising the visibility of repression (the indirect effect). Finally, we find that the first effect is driven by democratic countries or those with media freedom, suggesting that cellphone coverage has a larger effect where citizens are otherwise free to criticize or organize against government.

To alleviate concerns about selection bias, we perform placebo tests to ensure that differential trends prior to the extension of coverage do not explain our findings. We also include a time-varying measure of economic development in our models to demonstrate that our results are not driven by concomitant changes in economic activity. We show that our main result holds across event datasets that employ different methods for coding and geo-locating protests. Finally, we find no evidence of reporting bias in areas receiving cell phone coverage, and a bounding exercise suggests that any reporting bias would have to be large to explain away our main effects.

Our difference-in-differences design improves on past empirical work. Several past studies focus on already extant social movements where cell phones or social media are suspected to have catalyzed protests (e.g., Howard et al. 2011; Khamis and Vaughn 2011; Caren and Gaby 2011). While these studies are rich in detail, by selecting on the dependent variable, they can not rule out the possibility that these technologies have no effect - that there are contexts with comparable cell 
phone penetration that have seen no change in protest activity. Other studies rely on cross-sectional comparisons (e.g., Pierskalla and Hollenbach 2013, present primary results based on cross-sectional data). Such studies struggle to account for static differences across localities that do and do not receive coverage that may also affect the incidence of protest, such as, distance from the capital or ethnic composition. By contrast, our identification strategy exploits within-locality variation in cell phone access and protest, which eliminates confounds that do not vary within localities over our eight-year study period. Recent work by Manacorda and Tesei (2016) employs a similar identification strategy and concurs with our findings, but restricts attention to economically motivated protests in African countries.

While cell phones do not inspire political revolutions, we do find that these technologies enable mobilization by directly and indirectly reducing the costs of protesting.

\section{Extant Work on the Coordination and Containment of Protest}

Would-be protesters face formidable challenges. Protesting imposes private costs on participants: they have to gather information about the event, take time away from work or leisure, and risk being repressed. Even if an individual cares about a cause, he or she may only be willing to bear these costs if they are confident that others will join them. As a protest increases in size, its probability of success may grow, and each individual's likelihood of being targeted for repression declines (Kuran 1991, p. 18). Thus, the individual returns to protesting increase with the number of other individuals that participate. This type of strategic problem is commonly referred to as a coordination problem (Chwe 2001, p. 12). ${ }^{1}$

How do individuals solve these coordination problems? Consider the problem from the perspective of a single individual. A potential protester wants her compatriots to know that she is

${ }^{1}$ This is distinct from a free-rider problem. Although some past work asserts that cell phones help groups sanction free-riders, we focus on coordination problems, because of the many case studies illustrating how cell phones help individuals communicate about protest (see Kelly Garrett 2006). 
planning to protest. Knowing this, they may also want to participate, as their returns to protesting are higher if the original protester turns out. But before following through with her stated plan, she needs to know that her compatriots have heard her, and, furthermore, they need to know that she knows that they have heard her plans, and so on. That is, the potential protester's plan needs to be common knowledge (Aumann 1976). Several scholars have clarified the important role that public rituals and organized religion can play in the development of common knowledge (Chwe 2001; Patel 2007). We focus here on the role of communication technologies, such as cell phones, in generating common knowledge or almost common knowledge. ${ }^{2}$

First, in order for the potential protester to transmit her plan to take to the streets, she needs to be able to communicate with her compatriots. Better still, they should be able to communicate back and confirm that they heard her message. The ability to (reliably) transmit messages is then a necessary, if not sufficient, condition for generating common knowledge about would-be protesters' intentions. ${ }^{3}$ (If protesters prefer to share their intentions shortly before protesting to avoid preemptive arrests, then it also helps if they can communicate quickly.) Second, social media, which is increasingly accessed through mobile phones, provides a platform for users to share information about protests and know that others have seen their posts (e.g., think of the Like button on Facebook). ${ }^{4}$ Tufekci and Wilson (2012, p. 369) report that, in their sample of Egyptian protesters, just over 80 percent used their phones to communicate about the protests, roughly 50 percent used Facebook, and another 13 percent used Twitter. And this use of social media appears to have increased

\footnotetext{
${ }^{2}$ True common knowledge (with all of the implied higher order beliefs) rarely, if ever, exists in reality. We focus instead on almost common knowledge, a concept developed in Rubinstein (1989). ${ }^{3}$ Cell phones are not the only technology that can serve this function: centralized mass media, such as radio and television, can aid in coordination; however, these outlets can also be captured by the state (e.g., Kern and Hainmueller 2009; Warren 2015; Yanagizawa-Drott 2014).

${ }^{4}$ As of the Q2 2014, Facebook announced that $60 \%$ of its ad revenues were generated through mobile, and $30 \%$ of users only access the site from their phones (Hamburger 2014).
} 
protest activity: Enikolopov, Makarin and Petrova (2016), for example, find that social media penetration in Russia increases the probability of protest, as well as protest size. ${ }^{5}$

While most work on this topic argues that cell phones help coordinate protests, some suggest that these platforms actually reduce certain forms of political violence. In their study of insurgent violence in Iraq, Shapiro and Weidmann (2015) find that better cell phone coverage leads to a reduction in attacks at the district level. They argue that cell phones in Iraq enable more effective surveillance of rebel activity - an insight that is then formalized in Shapiro and Siegel (2015). ${ }^{6}$ Closer to our own focus on protest, Hassanpour (2014, p. 4) argues that cell phones and social media might "discourage face-to-face communication and mass presence in the streets ... [and] create greater awareness of risks involved in protests, which in turn can discourage people from taking part in demonstrations." He shows that a sudden country-wide disruption of communications networks in Egypt led to more protests within Cairo. Given these findings, it remains an open empirical question whether cell phone access increases the probability of protest.

Faced with a protest, when does the government employ repression? In earlier work (from the 1950s to 1970s), repression was not regarded as a choice, but rather as a characteristic of regimes. Davenport (2007, p. 4) notes that repression was seen as a "pathology ...that political leaders were simply compelled to take because of some system deficiency." More recent theoretical work treats governments as rational actors, weighing the benefits and risks associated with repression.

First and foremost, repression imposes a cost on its targets and can, thus, deter or demobilize

${ }^{5}$ King, Pan and Roberts (2013) find that Chinese censors focus attention on internet posts related to mobilization, revealing concern about the role that social media plays in catalyzing dissent.

${ }^{6}$ While insurgency and protest are both forms of political violence, they impose different costs on citizens. In the model developed in Shapiro and Siegel $(2015,316)$, the community wants to aid in surveillance if this shields them from insurgent violence. However, unlike insurgency, protests do not often result in violence against non-participants. Thus, citizens do not have the same strong incentive to actively collaborate with the government (e.g., call in tips) against potential protesters. 
dissidents (Balbus 1973; Garfias et al. 2016; Lichbach 1984; Opp and Roehl 1990; Pierskalla 2010). A second common argument contends that repression serves as a signal of either the government's resolve or strength (e.g., Walter 2006). In Pierskalla (2010), for instance, governments opt for repression because they worry that challengers view the decision to accommodate protesters as a sign of weakness. From the government's perspective, repression can demobilize protesters, or signal its capacity to fend off future challengers, or both.

Despite these upsides, governments sometimes exercise restraint. Repression may simply be costly: protest policing requires equipment and personnel, and governments have finite budgets. Other scholars argue that governments pay costs for violating international laws and norms against human rights abuses (Hafner-Burton 2005; Hendrix and Wong 2013). However, the most widespread explanation for restraint does not focus on these costs, but rather the possibility that repression inflames dissent and, thus, fails to serve its intended purpose. Goldstone and Tilly (2009, p. 181) summarize a number of case studies, which find evidence that repression backfired: “Khawaja’s (1993) study of Palestinian protest in the West Bank, Rasler’s (1996) study of Iranian protests in 1977-79, Francisco's (1996) study of protest in Germany, and Olivier's (1990) study of Black protest in South Africa all find, as the latter clearly states, that 'the effect of repression on the rate [of collective action] is not negative! Repression led to a significant increase in the rate of collective action."'7

Scholars have rationalized this finding by arguing that repression can push previously docile citizens to openly oppose the government. Opp and Roehl (1990, p. 524) summarize several reasons why repression might engender a backlash. First, "repression may thus be regarded as immoral, and individuals who are exposed to repression or who know about it may feel a moral obligation to support a movement's cause and even to regard violence as justified." Second, "repression may cause system alienation, i.e., discontent with a society's political institutions, which will in turn lead

${ }^{7}$ Lawrence (2017) provides more recent evidence from Morocco that information about police brutality increased support for the movement's vanguard. 
to more protest if persons believe they can change these conditions by means of protest." Taken together, this work suggests that repression is a double-edged sword: it can both discourage and justify dissent.

Less work has been done to enumerate the conditions under which repression extinguishes or exacerbates protest. Siegel (2011, p. 1005) provides a notable exception: he argues that if the targets of repression do not have many ties that extend beyond their locality, then outrage is unlikely to spread: "anger has little aggregate effect when network structure doesn't allow it to spread. However, once there is a sufficient number of weak ties, anger-driven participation can spread throughout the network rapidly enough to overwhelm repression and trigger a backlash." By this logic, governments should worry more about generating a backlash when information about their use of repression can spread quickly and widely among the citizenry.

\section{Coordination of Protests, Repression, and Escalation}

Our argument synthesizes and extends this prior work by considering how new communication technologies affect the decisions of protesters, governments, and citizens. We formalize the argument in section A, but focus here on the intuition.

When deciding whether to stage a protest, individuals consider the costs, which are affected by others' participation and the risk of repression. Each potential protester cares about what others do, because there is strength and protection in numbers. The government, unwilling or unable to immediately concede to the protesters' demands, can choose to repress. Repression imposes a cost on protesters, but it can also outrage citizens, bringing more people out into the streets, escalating the demonstration. The case studies and survey evidence cited above suggest that witnessing repressive acts can invokes sympathy and support for protesters. The government must then weigh the deterrent effect of repression against the risk of escalation.

We argue that cell phones enable collective action when groups want to mobilize. First, cell phones reduce the costs of coordination. Where potential protesters can quickly exchange information about where or when a demonstration will be staged, they reduce uncertainty about how to 
participate. This reduces the costs of turning out and, thus, increases the probability of protest the direct effect.

Second, where the cell network is extensive, gaining coverage connects a community to a large proportion of their fellow citizens. If a protest occurs in this newly covered community, information about any government response can now be widely broadcast. We argue that some (though not all) citizens sympathize with protesters and punish the government if they witness harsh repression. Anticipating this backlash, the government exercises greater restraint should a protest occur the newly covered community. This reduces protesters' expected costs of repression and, thus, further increases the probability of protest - the indirect effect. ${ }^{8}$ Hence, the effect of gaining coverage on the occurrence of protest should be greater where a large proportion of citizens are connected to the cell phone network, i.e., where a bigger audience bears witness to any repression. (These comparative statics are stated more formally in proposition 2, in section A.1 of the appendix.)

We take these two predictions to the data:

(H1) Gaining access to cell phone networks increases the probability of protest.

(H2) This effect on the probability of protest is larger when a greater share of the population already has access to the cell phone network.

We also look for evidence that cell phone access reduces the probability of repression. Our prediction is that cell phones should reduce the use of repression, though this is a more difficult claim to evaluate given sample selection concerns discussed in section $\mathrm{C}$ of the appendix.

\footnotetext{
${ }^{8}$ In the conjectured equilibrium, repression and the resulting backlash are off the equilibrium path. While bystanders will not be provoked to join the demonstration, the initial group of protesters faces lower costs to mobilizing when there is no risk of repression.
} 


\section{Empirical Strategy}

\subsection{Estimating the Effect of Coverage on Protest}

To evaluate the first hypothesis, we look for changes in the probability of protest after an area receives access to a cell phone network and compare these changes to trends in localities that remain outside of the network. Concretely, we estimate the difference-in-differences between areas that receive coverage during our study period and those that do not, using the following specification:

$$
y_{i t}=\alpha_{i}+\beta_{t}+\gamma D_{i t}+\delta X_{i t}+\varepsilon_{i t}
$$

where $i$ indexes a locality, $t$ indexes years, $D_{i t}$ is an indicator variable for whether a locality is covered in year $t$, and $X_{i t}$ is a matrix of time-varying covariates. $\alpha_{i}$ and $\beta_{t}$ are locality and year-specific intercepts. Our dependent variable, $y_{i t}$, is an indicator for whether area $i$ had a protest in year $t$. If gaining access to cell phone networks increases the probability of protest, then $\gamma$ should be positive, indicating that the likelihood of protest increases by a larger magnitude after localities receive coverage relative to the change observed in uncovered areas.

Our second prediction is that gaining access to a cell phone network should have a larger effect on the probability of protest when the proportion of citizens already connected to the network (which we denote as $m_{c t}$ ) is large. In short, if an area is suddenly able to communicate with most of the country due to its inclusion in the communication network, we expect that access to the network will have a larger impact on protest activity. To estimate this heterogeneous effect, we amend equation 1 slightly:

$$
y_{i t}=\alpha_{i}+\beta_{t}+\gamma D_{i t}+\zeta m_{c t}+\eta D_{i t} * m_{c t}+\delta X_{i t}+\varepsilon_{i t}
$$

where $m_{c t}$ is the proportion of people in $i$ 's country $c$ that are covered in time $t$. The second hypothesis implies that $\eta$ should be positive. In estimating all of these models, we cluster our standard 
errors at the locality level unless otherwise noted.

Our empirical strategy does not assume the as-if random assignment of cell phone coverage. Any static differences across areas that do and do not receive coverage will not confound our analysis. We agree that whether, for example, a cell falls within the boundaries of the capital city, or whether it experienced a history of armed conflict or repression could affect both the likelihood of protest and cell phone coverage. However, our cell fixed effects account for these and all other features, which do not vary over our eight-year time window.

We make less restrictive assumptions to obtain consistent estimates of $\gamma$. To recover the causal effect (technically, the average treatment effect on the treated) of cell phone coverage, we need (1) areas that do and do not receive treatment to follow parallel trends in the absence of treatment, and (2) that coverage expansion into one area does not affect protest or repression in other areas. ${ }^{9}$

The parallel-trends assumption would be violated by omitted, time-varying characteristics that are correlated with cell phone coverage and affect protest incidence. While this assumption is untestable, it is commonly bolstered by demonstrating that treatment and control areas follow similar trends prior to treatment. First, we show that the increase in protest does not anticipate our treatment (figure 2). This suggests that the areas that receive coverage are not undergoing changes (e.g., urbanization) immediately prior to coverage that also make them more inclined to protest. Second, a falsification test that assigns treatment well before it actually occurs also reveals no differential trends prior to the extension of coverage. Third, we include country $\times$ year fixed effects in selected models, i.e., flexible, country-specific time trends. These terms absorb any features that vary at the country-year level (e.g., regime or economic downturns). Finally, we also include a time-varying measure of economic development, nighttime luminosity, to address concerns about modernization driving both the expansion of coverage and protest.

\footnotetext{
${ }^{9}$ More technically, we require that $E\left(\varepsilon_{i t} \mid D_{i t}, \alpha_{i}, \beta_{t}\right)=0$. Consistent estimates of $\eta$ additionally require the conditional exogeneity of the proportion of citizens with coverage, $E\left(\varepsilon_{i t} \mid D_{i t}, m_{c t}, \alpha_{i}, \beta_{t}\right)=0$.
} 
We address concerns about non-constant treatment effects and violations of SUTVA through the specific functional form in equation 2. This specification allows for both the heterogeneous treatment effects and the spillover suggested by our model.

\subsection{Estimating the Effect on Repression}

Finally, if cell phones expand the number of citizens that witness repression and, thus, discourage authorities from clashing with demonstrators, then the frequency of repression should decline as areas transition into cell phone coverage. We estimate:

$$
r_{i t}=\alpha_{i}+\beta_{t}+\tau D_{i t}+\delta X_{i t}+\varepsilon_{i t}
$$

where $r_{i t}$ is an indicator for repression in locality $i$ in year $t$. Even granting the standard differencein-differences assumptions above, estimating the effect of coverage on repression remains challenging. This is because repression is only observed when a protest actually takes place and not when a protest that would have been repressed never materializes (i.e., when repression effectively deters protest). If we could somehow observe every instance where repression would have been employed whether or not a protest took place, we expect that $\tau<0$.

Fortunately, our theoretical model allows us to make empirical progress, as it predicts, for different parameter values, how cell coverage affects the use of repression and when that is observable. Assuming our model is correct, we show in section $\mathrm{C}$ of the appendix that our estimate of $\tau$ will understate the true reduction in repression if we exclude localities where the costs of staging a protest are prohibitively high. To remove such places, we drop localities that never experience a protest before their first year of cell coverage. Estimating equation 3 using the resulting sample, we feel more confident about interpreting our estimate of $\tau$ as an attenuated estimate of the negative effect of coverage on repression; nonetheless, these results should be regarded cautiously. 


\section{Data}

\subsection{Cell Phone Coverage}

To measure cell phone coverage over time, we rely on the Collins Mobile Coverage Explorer database, which is based on submissions made by telecom operators around the world. The data has a nominal resolution of approximately $1 \mathrm{~km}$ on the ground, and is available yearly for the period 2007-2014, except for 2010. ${ }^{10}$ Pierskalla and Hollenbach (2013) employ data from the same source, albeit for a shorter time span and only for African countries.

As figure 1 shows, cell phone coverage increased substantially during the 2007-2014 period, though larger urban areas and developed countries already had (near) complete coverage prior to 2007. In the empirical analysis, we leverage variation from the areas that undergo a change in their coverage status during the period of study (marked in black) and exclude areas that are covered throughout the entire study period. ${ }^{11}$ In section D.4, we compare the proportion of the population

${ }^{10}$ Our maps show coverage areas in quarter 1 (Q1) of 2007, Q1 2008, Q1 2009, Q4 2011, Q4 2012, Q4 2013. We use the 2007, 2008, and 2009 maps to code treatment in those years. However, for the 2011, 2012, and 2013 data, we use these maps to code treatment in the following year. That is, if an area has coverage in the last quarter of 2011, we code it as treated from 2012 forward. This decision avoids coding areas as treated before they actually receive coverage. However, it comes at the cost of coding some areas as control when they had access to the cell network for part of the year. If cell phones increase protest incidence, this coding decision should make it harder to find such an effect.

${ }^{11}$ The coverage data includes GSM (2G), 3G and 4G mobile standards. Some countries - notably the US - phased in GSM from CDMA/IS-95. For these areas, we could incorrectly assign a change in treatment, when the data simply reflects a change in standards. This problem affects very few countries: in Africa, for example, GSM accounted for 90\% of market share by 1999 (Selian 2001). Given that our results hold in a sample of African countries and when we exclude 2007 (the year of concern), we feel confident that changes in mobile standards do not drive our findings. Our analysis 
Figure 1: Expansion of Cell Phone Networks, 2007-14 Cell phone networks expanded, esp. in low-and middle-income countries.

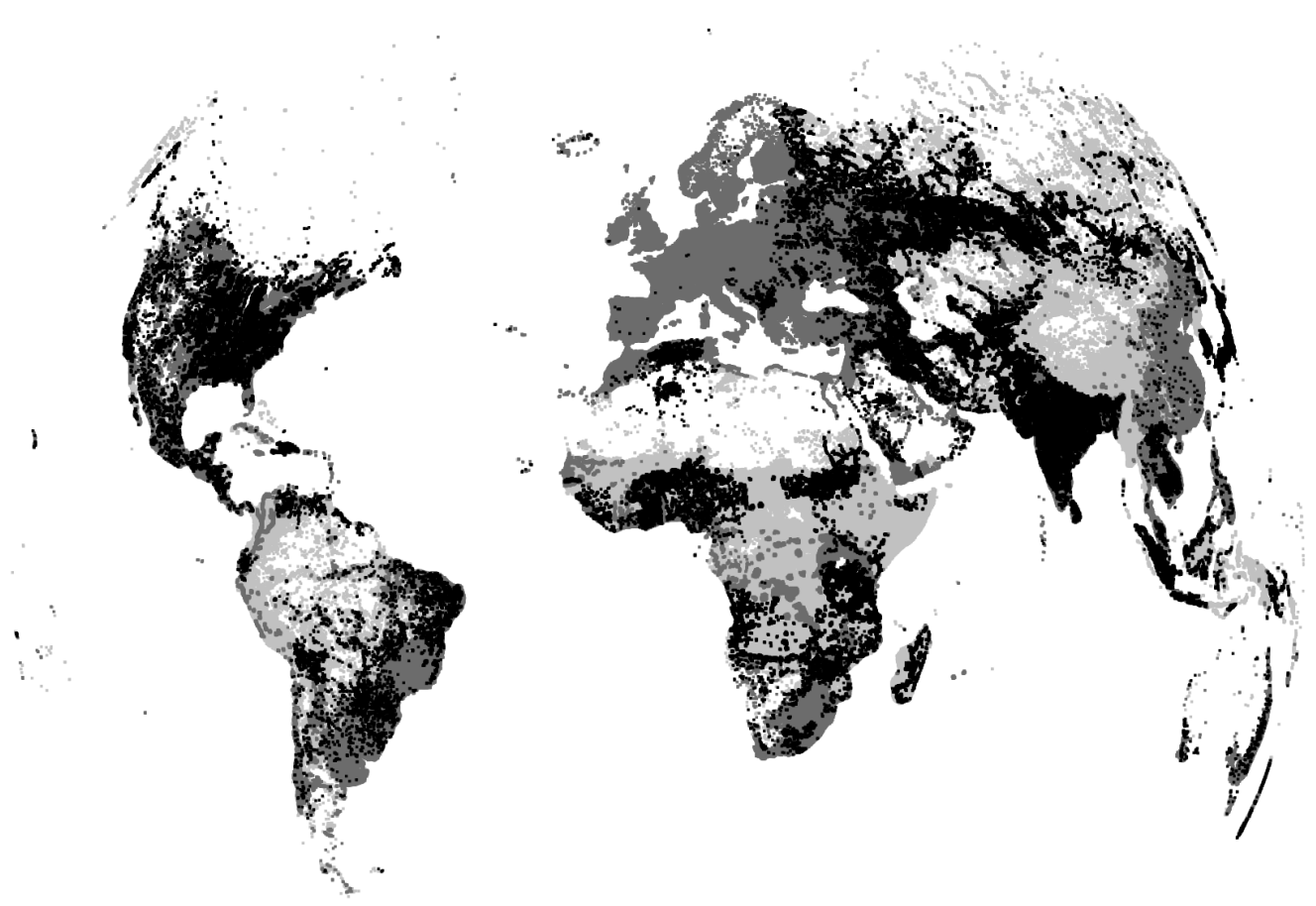

This figure is based on the Collins Mobile Coverage Explorer database. We restrict attention to populated areas. Darker grey indicates areas that are covered throughout the study period; black, areas that receive coverage between 2007 and 2014; and light grey, areas uncovered as of 2014. This map is based on a 1\% sample of $1 \mathrm{~km}^{2}$ cells.

covered in every country-year according to the Collins Mobile Coverage Explorer database with data on cell phones per capita from Banks and Wilson (2014). Reassuringly, these variables are highly correlated $(\rho=0.62)$, indicating a strong positive association between access to, and the uptake of, mobile technology.

Our geographic unit is the $6 \mathrm{~km}^{2}$ grid cell (at the equator). We discuss this aggregation decision below, which is motivated by our recognition that protest events are often geo-coded using cities or towns, which can span multiple $1 \mathrm{~km}^{2}$ cells. We code units as treated if at least half of their area is covered in a given year. Alternatively, we can code units as treated if any of it is covered; this

is also robust to removing any country from the sample. 
decision does not affect our results.

\subsection{Protest Events}

\section{Global Database of Events, Location, and Tone}

The Global Database of Events, Location, and Tone (GDELT) uses tools from text analysis to machine code events from a wide array of news sources (Leetaru and Schrodt 2013). GDELT includes a number of different types of events, but we only extract the protests which occurred between 2007 and August 2014 and can be geo-located based on the name of specific city or landmark. That is, we only retain protest events with the most precise geo-codes. ${ }^{12}$

GDELT errs on the side of inclusion and, thus, contains more false positives than other event databases. However, we do not believe this introduces any bias into our analysis. First, we show that our results hold using the Social Conflict in Africa Database, which is hand-coded. Second, our empirical strategy leverages trends - not level differences - in protest activity, and head-to-head comparisons suggest that GDELT captures important changes in protest activity (Steinart-Threlkeld 2014). Ward et al. (2013) look at events in Egypt, Syria, and Turkey as reported in GDELT and ICEWS, a warning system used by the US government. They find that "the volume of GDELT data is very much larger than the corresponding ICEWS data, but they both pick up the same basic protests in Egypt and Turkey, and the same fighting in Syria" (p. 10). Finally, we include both locality and year (or country-year) fixed effects in our models. These absorb any time-invariant variation in protest levels at the grid cell level (e.g., due to geography), as well as global trends in protest incidence (e.g., due to changes in the corpus of news sources used to code GDELT events).

Protest events are typically assigned coordinates based on the town or city that they occur in. We construct grid cells that are $6 \times 6$ kilometers in dimension, as this corresponds to the median area of major towns or cities according to Oak Ridge National Laboratory (2012). Our results are

${ }^{12}$ GDELT avoids double-counting by aggregating stories covering the same event. While work by Manacorda and Tesei (2016) uses logged counts from the GDELT data, we employ a binary indicator for protest as the dependent variable to limit concerns about over-counting. 
robust to different cell sizes: our estimates are of the same magnitude (relative to the sample mean) if we use smaller $\left(1 \mathrm{~km}^{2}\right)$ or larger $\left(24 \mathrm{~km}^{2}\right)$ grid cells. ${ }^{13}$ In section D.7, we restrict attention to major cities and find support for our hypotheses using the city-year as the unit of analysis.

\section{Social Conflict in Africa Database}

We also use event data on protests, riots, and strikes from the Social Conflict in Africa Database (SCAD) (Hendrix and Salehyan 2012). The SCAD is culled from Associated Press and Agence France Presse news wire stories for African countries (1990-2011). A pool of stories that contain key words associated with mobilization or violence are sorted, read, and hand-coded. Events only enter the data one time, but multiple locations (e.g., a simultaneous protest across different cities) receive separate entries with distinct coordinates. The SCAD excludes all events that take place within the context of an armed civil conflict (as defined by the start and end dates in the Uppsala Armed Conflict Database). As with GDELT, we only use those protests with precise geo-codings.

The SCAD is especially useful for our purposes, because it includes an indicator for whether the event was repressed. We use this variable to assess whether cell phone coverage reduces the probability of repression.

\section{Integrated Crisis Early Warning System}

Finally, we corroborate our results with the Integrated Crisis Early Warning System (ICEWS), produced by Lockheed Martin, which draws on commercially available news sources from approximately 300 publishers, including both international and national publishers (Boschee et al. 2015). Like GDELT, ICEWS machine codes events using the Conflict and Mediation Event Observations (CAMEO) system, which includes a top-level category for protest (Schrodt and Yilmaz 2007). The dataset covers all countries over the period from 1995 to 2014. We restrict our sample to more precisely geo-located events that include the name of a specific city or town. An evaluation by human

${ }^{13}$ We recognize that the geo-coding procedure may amplify protest counts in some cells (e.g., the centroids of towns). Such level-differences across cells will be absorbed by our fixed effects and, thus, not affect our estimates. 
coders found that nearly 85 percent of sampled protest events correctly identified the event type and actors (Raytheon BBN Technologies 2015, 8). As noted above, ICEWS complements the GDELT data by applying a more restrictive filter; if GDELT risks over-reporting, ICEWS risks omitting events (Ward et al. 2013). ${ }^{14}$

\subsection{Other Covariates}

Oak Ridge National Laboratory (2012) provides global population estimates at the $1 \mathrm{~km}^{2}$ resolution. We employ the 2012 data in our analysis. Ideally, we would have population data for each grid cell-year in our panel. However, we heed the advice of the data creators, who caution against over time comparisons. We use this population data, first, to remove grid cells with zero population and, second, to calculate $m_{c t}$, the proportion of citizens covered by the cell phone network in country $c$ in year $t .^{15}$

If cell phone expansion is driven by demand, then coverage may follow economic development. These economic changes could increase the likelihood of both coverage and protest, confounding our estimates. While yearly income or consumption data does not exist for every square kilometer of the globe, we can use information on nighttime lights collected by the Defense Meteorological Satellite Program's Operational Linescan System (DMS-OLS) at the $1 \mathrm{~km}^{2}$ resolution from 2006 to 2013. A number of studies have demonstrated a robust positive correlation between nighttime lights and other indicators of development (Chen and Nordhaus 2011; Doll, Muller and Morley 2006). In a recent paper, Weidmann and Shutte (2017) correlate luminosity data and responses from geo-referenced household surveys to show that "light emissions are highly accurate predictors of economic wealth."

\footnotetext{
${ }^{14}$ In appendix D.8.3, we show that cell coverage does not lead to a divergence in protest reports across the datasets, suggesting that cell coverage is not amplifying reporting bias in the GDELT data relative to other datasets.

${ }^{15}$ Suppose that there are $N$ grid cells in country $c, m_{c t}=\left(\sum_{i=1}^{N} \mathbb{1}(\text { Covered })_{i t} \times \operatorname{Pop}_{i}\right) /\left(\sum_{i=1}^{N}\right.$ Pop $\left._{i}\right)$.
} 
We employ the "Average Lights $\mathrm{x}$ Pct" measure, which assigns each cell a number from 0 to 63 , representing its luminosity multiplied by the percent frequency of light detection. To calculate the luminosity within our larger, $6 \mathrm{~km}^{2}$ grid cells, we simply take the average across the 36 nested 1 $\mathrm{km}^{2}$ grid cells.

To evaluate whether our estimates vary by regime type or media freedom, we employ data from the Polity IV (available through 2014) and Global Media Freedom (available through 2012) projects (Whitten-Woodring and Van Belle 2014; Marshall, Jaggers and Gurr 2012). We consider a country to be democratic if its polity score exceeds five in a given year. Countries scoring between $[-5,+5]$ are often described as anocracies; countries falling between $[-10,-6]$, full-blown autocracies. The Global Media Freedom dataset places countries in three different categories: free (open criticism), imperfectly free (social, legal, or economic costs to criticizing the government), not free, or no effective national media. To aid in the interpretation, we dichotomize this variable into free or not.

\section{Results}

\subsection{Cell Coverage and the Probability of Protest}

We evaluate our first two hypotheses by estimating equations 1 and 2 using both the GDELT and SCAD. To recap, we expect that cell phone coverage increases the probability of protest and that this effect will be largest where a large proportion of the citizenry is already a part of the network (i.e., where cell phones connect localities to a larger audience).

Before presenting the main estimates, we start by reporting the probability of protest for three groups in table 1: (a) areas that never receive coverage, (b) treated areas prior to treatment, and (c) treated areas after they have gained access to the network. Among those areas that eventually receive coverage, the probability of protest is over twice as large after they transition into coverage. These simple comparisons foreshadow our regression results. This table also highlights an important feature of the data: we are looking at the probability of protest in a given $6 \mathrm{~km}^{2}$ grid cell in a given 
year. Our sample has over two million populated grid cells, so that probability is small in absolute terms. In interpreting the magnitude of our effects, it is important to keep in mind this low baseline probability.

Table 1: $\operatorname{Pr}$ (Protest) by Coverage; GDELT Data

\begin{tabular}{cccc}
\hline \hline Never Covered & $\mathbb{1}$ (Covered) & $\operatorname{Pr}($ Protest $) \times 100$ & St. Dev. \\
\hline 1 & 0 & 0.050 & 2.228 \\
0 & 0 & 0.185 & 4.302 \\
0 & 1 & 0.458 & 6.750 \\
\hline
\end{tabular}

Two figures help convey our main results and the credbility of our empirical strategy. First, in the left panel of figure 2, we graph the trends in the probability of protest in both control and treatment grid cells. This figure shows that prior to transitioning into coverage, both groups follow roughly parallel trends; yet, after receiving cell phone coverage, the probability of protest increases substantially more in treated grid cells relative to control areas. In the right panel of figure 2 we estimate the change in the probability of protest in the years before and after grid cells transition to coverage (relative to the areas that have not yet transitioned). To estimate this model, we include both leads and lags of our treatment variable in equation 1 (See Autor 2003, Fig. 3, for an early implementation of this strategy). This figure conveys two similar points. First, as with the simple difference-in-differences visualization, there is no evidence that the probability of protest was increasing prior to coverage in the grid cells that eventually receive treatment; finding no evidence of anticipation bolsters the identifying assumption that treatment and control areas would have followed parallel trends in the absence of treatment. Furthermore, the treatment effect is not immediate, but rather increases with time. We do not expect the introduction of cell phone coverage to immediately incite protest; only after citizens adopt the technology can it have the effect of enabling collective action.

In table 3, we report the estimates from equations 1 and 2. The first two models estimate 
Figure 2: Effect of Coverage Expansion on Pr(Protest); GDELT Data

Trends in Pr(Protest) are parallel prior to treatment, but Pr(Protest) increases after cell phone coverage.

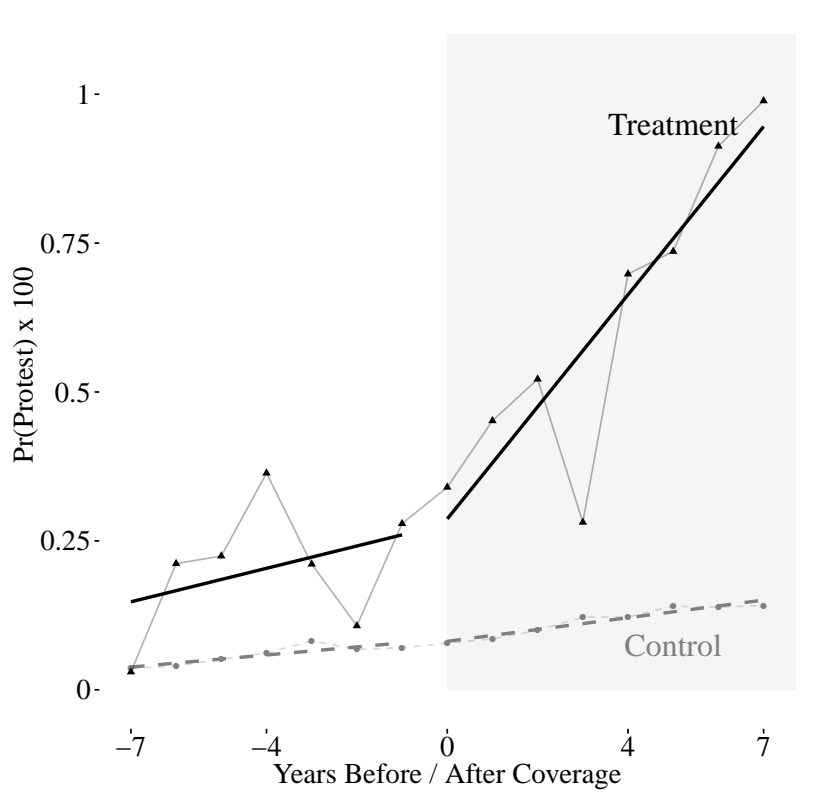

(a) Visualizing Difference-in-Differences
1 -

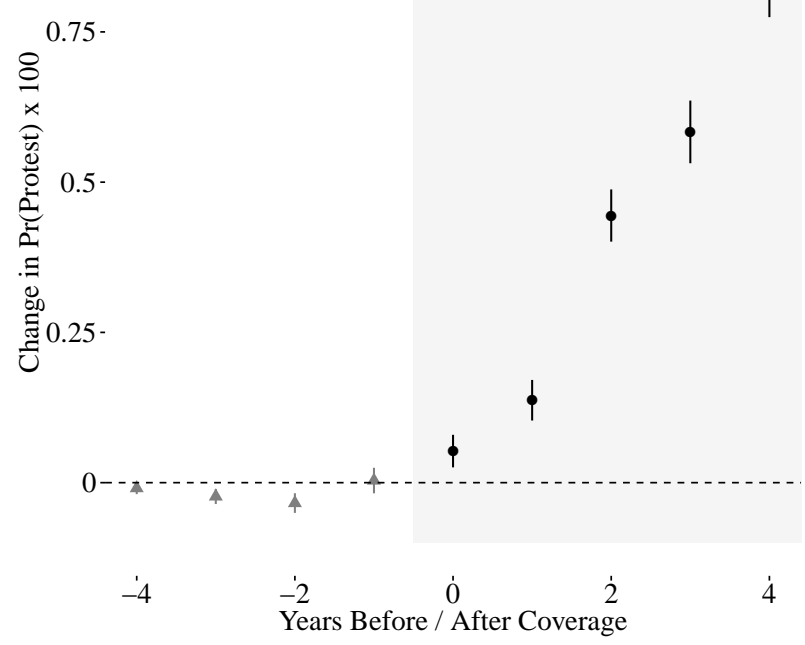

(b) Leads/Lags Plot

The figure on the left plots the probability of protest in the years before and after coverage. The figure on the right displays the point estimates and 95\% confidence intervals on four leads and lags of our treatment variable. We use protest information from 2000-14 to construct the lead/lags to avoid losing observations. The final lag is equal to 1 for every year beginning with the fourth year after coverage. The sample used is limited to grid cells that experience a change in treatment status.

the most straightforward difference-in-differences, only including an indicator for whether a grid cell has access to the cell phone network in a given year. The first model includes grid cell and year fixed effects, while the second model substitutes the year fixed effects for country $\times$ year fixed effects, flexibly accounting for country-specific trends in the probability of protest. The differencein-differences estimate from model 1 implies that the transition to coverage increases the probability of protest by roughly half the baseline probability in treated areas. ${ }^{16}$ Model 4 demonstrates that this result is robust to including our proxy for economic development (logged luminosity, lagged one

${ }^{16}$ The effect size grows for more densely populated areas (see section D.2). If we look, for example, at grid cells with more than 36,000 inhabitants - a population density of 1,000 inhabitants per $\mathrm{km}^{2}$ - the effect increases to 1.97 (see table A.4). 
year), suggesting that the effect is not driven by modernization that could both generate demand for coverage and protest.

Table 2: Summary Statistics: GDELT Data

\begin{tabular}{lccccc}
\hline \hline Statistic & $\mathrm{N}$ & Mean & St. Dev. & Min & Max \\
\hline $\mathbb{1}($ Protest $) \times 100$ & $12,661,254$ & 0.150 & 3.867 & 0 & 100 \\
$\mathbb{1}$ (Covered) & $12,661,254$ & 0.178 & 0.383 & 0 & 1 \\
$m$ & $12,661,254$ & 0.758 & 0.247 & 0.000 & 1.000 \\
Log Luminosity $t-1$ & $12,661,254$ & 0.284 & 0.573 & 0.000 & 4.159 \\
\hline
\end{tabular}

Our second hypothesis states that the effect of cell phone coverage should be larger where access to the cell network connects a locality to a large proportion of their fellow citizens. We expect the interaction of our coverage indicator and the proportion of each country's population connected to the cell phone network $\left(m_{c t}\right)$ to be positive. In both models 3 and 5 , we find that the coefficient on the interaction term is both positive and significant. Our linear interaction term in model 3 implies that the effect of coverage on protest is positive when $m_{c t}$ exceeds 0.7 , which occurs around the 6th percentile of $m_{c t}$ for the covered cells in our sample (see figure A.4 for the distribution of $m_{c t}$ ). We caution against reading too much into the implied effect of coverage at very low-levels of $m_{c t}$. First, there are not many treated cells in this range. Second, when we look at the effect of coverage on protest for cells that fall below the median level of $m$, we find that the effect is smaller but still positive. Figure A.3 reports the effect of coverage for different terciles of $m_{c t}$.

We also explore whether the effect of cell phone access on protest is larger in states that limit political competition or effectively censor mass media. In table A.2 of the appendix, we interact our treatment variable with indicators for whether a country is democratic (according to Polity IV) or allows the media to function freely. We find that the positive effect of cell phone coverage on protest is driven by more democratic states. This result permits a number of interpretations: in relatively closed countries, government may be able to shut down these communication networks; 
Table 3: Coverage Expansion and Pr(Protest); GDELT Data Cell phone coverage increases $\operatorname{Pr}\left(\right.$ Protest), esp. where audience $\left(m_{c t}\right)$ is large.

\begin{tabular}{|c|c|c|c|c|c|}
\hline & \multicolumn{5}{|c|}{ Dependent variable: } \\
\hline & \multicolumn{5}{|c|}{$\mathbb{1}($ Protest $) \times 100$} \\
\hline & $(1)$ & $(2)$ & (3) & $(4)$ & $(5)$ \\
\hline $\mathbb{1}$ (Covered) & $\begin{array}{c}0.088 \\
(0.006)\end{array}$ & $\begin{array}{c}0.037 \\
(0.006)\end{array}$ & $\begin{array}{l}-0.251 \\
(0.053)\end{array}$ & $\begin{array}{c}0.085 \\
(0.006)\end{array}$ & $\begin{array}{l}-0.237 \\
(0.053)\end{array}$ \\
\hline$m$ & & & $\begin{array}{c}0.096 \\
(0.021)\end{array}$ & & $\begin{array}{c}0.097 \\
(0.021)\end{array}$ \\
\hline $\mathbb{1}($ Covered $) \times m$ & & & $\begin{array}{c}0.362 \\
(0.056)\end{array}$ & & $\begin{array}{c}0.344 \\
(0.056)\end{array}$ \\
\hline $\log _{\text {Luminosity }_{t-1}}$ & & & & $\begin{array}{c}0.033 \\
(0.007)\end{array}$ & $\begin{array}{c}0.028 \\
(0.007)\end{array}$ \\
\hline Cell FEs & $2,110,209$ & $2,110,209$ & $2,110,209$ & $2,110,209$ & $2,110,209$ \\
\hline Year FEs & 6 & & 6 & 6 & 6 \\
\hline Country $\times$ Year FEs & & 1,236 & & & \\
\hline Observations & $12,661,254$ & $12,661,254$ & $12,661,254$ & $12,661,254$ & $12,661,254$ \\
\hline
\end{tabular}

Note:

Robust std. errors clustered on grid-cell.

Notes: columns 1-5: linear probability model regressions, where the dependent variable has been multiplied by 100 . See equations 1 and 2 for the econometric specifications. The unit-of-analysis is the grid cell-year (grid cells measure $6 \times 6 \mathrm{~km}$ at the equator). Grid cells with no population according to the LandScan data in 2012 are excluded from the sample, as are all grid cells covered throughout the study period. Data for the dependent variable comes from GDELT from 2007-09 and 2012-14; only protests with precise geo-codes are used. Information on mobile coverage is taken from the Collins Mobile Coverage Explorer database. Luminosity data (lagged one year) comes from the Defense Meteorological Operational Linescan System.

alternatively, repression may be already expected in these contexts and, thus, unlikely to incite additional anger and a backlash among bystanders. Finally, traditional media that can freely express criticism may further amplify information about government repression. Whatever the mechanism, cell phones have smaller direct and indirect effects in these settings. ${ }^{17}$

As a further check that trends in the treatment and control areas are parallel prior to the

${ }^{17}$ We also find that the indirect effect of cell phone coverage is larger in democracies (see table A.3). 
expansion of cell coverage, we conduct a falsification test. First, we re-assign treatment eight years before the actual extension of coverage, and then estimate the difference-in-differences using data on protest from 1999-2005 period. ${ }^{18}$ For example, a place that receives coverage in 2012 is assigned placebo coverage starting in 2004. Under the parallel trends assumption, we expect no effect of this placebo treatment on the probability of protest.

Figure 3: Difference-in-Differences using Placebo Treatment (1999-2005)

$\operatorname{Pr}$ (Protest) is unaffected by placebo cell phone coverage.

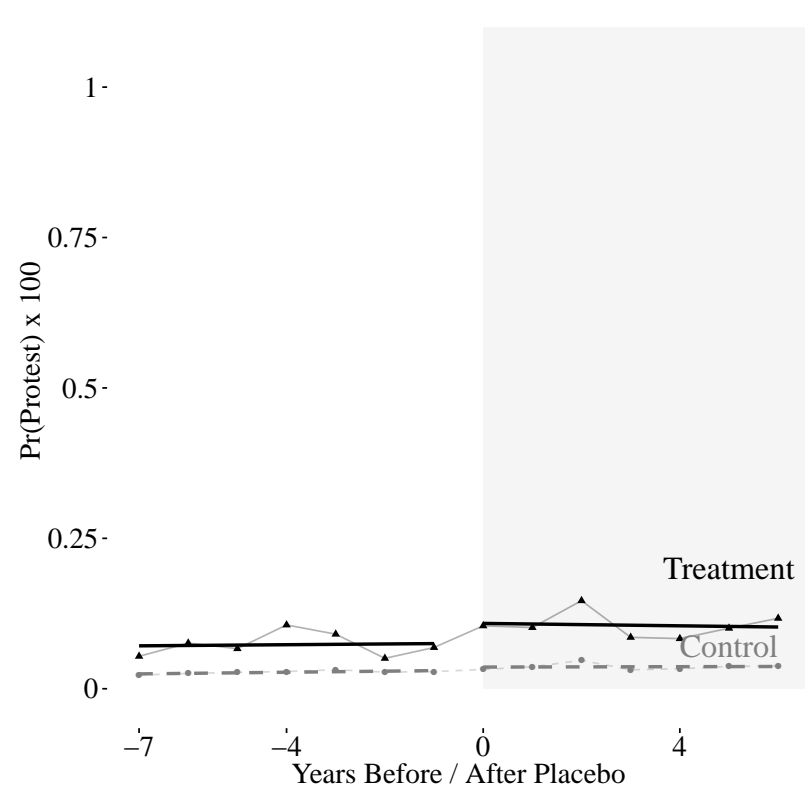

The figure plots the probability of protest in the years before and after a placebo treatment that occurs eight years prior to the actual treatment.

Using GDELT data, figure 3 plots probability of protest in each year before and after a placebo transition into coverage. The levels for the placebo treatment are different from the actual transition into cell phone coverage in figure 2, suggesting a general upward trend in the overall probability of protest over time. Crucially, while the actual treatment generates a substantial increase in the

\footnotetext{
${ }^{18}$ We exclude 2006 from this analysis to avoid wrongly coding areas as untreated when, in fact, they transitioned to coverage during 2006 but are first reported as covered in Q1 2007.
} 
probability of protest following coverage, the placebo does not.

The pattern revealed in the figure is confirmed in table 4 , where we repeat our main analysis with the placebo treatment and estimate equations 1 and 2 . The point estimate of placebo coverage is precisely estimated and close to zero in all models. For instance, model 2, which includes countryyear fixed effects in addition to grid cell fixed effects, indicates that the the real estimated effect is over fifteen times larger than the placebo result. Estimating equation 2, we also find no evidence that the placebo effect varies with $m$; the coefficient in table 4 , model 3 is a precisely estimated zero.

Table 4: Placebo Treatment and Pr(Protest); GDELT Data Placebo test indicates no secular upward trend in treatment areas.

\begin{tabular}{lccc}
\hline \hline & \multicolumn{3}{c}{ Dependent variable: } \\
\cline { 2 - 4 } & \multicolumn{3}{c}{$\mathbb{1}($ Protest $) \times 100$} \\
& $(1)$ & $(2)$ & $(3)$ \\
\hline $\mathbb{1}$ (Covered) & 0.0111 & 0.0024 & 0.0012 \\
& $(0.0037)$ & $(0.0041)$ & $(0.0334)$ \\
$m$ & & & 0.1296 \\
& & & $0.0149)$ \\
$\mathbb{1}$ (Covered) $\times m$ & & & -0.0012 \\
& & & $0.0353)$ \\
Cell FEs & & & $2,110,209$ \\
Year FEs & $2,110,209$ & $2,110,209$ & 5 \\
Country $\times$ Year FEs & 5 & & 1,030 \\
Observations & $10,551,045$ & $10,551,045$ & $10,551,045$ \\
\hline \hline Note: & \multicolumn{2}{c}{ Robust std. errors clustered on grid-cell }
\end{tabular}

Notes: columns 1-2: linear probability models. See equation 1 for the specification and table 3 for notes on data sources. Data for the dependent variable comes from GDELT from 1999-2001 and 2004-2005.

In addition to this falsification test, we also perform a number of robustness checks. First, we replicate our analysis using the ICEWS data in appendix D.8.1. While ICEWS reports lower levels of protest, the percentage change we estimate for cells transitioning to coverage is compara- 
ble across the datasets. Second, to address potential spatial dependence, we cluster our standard errors on larger geographic units, such as $24 \mathrm{~km}^{2}$ grid cells (see section D.6); our inferences are unchanged. Third, we also estimate the overall effect of coverage using the SCAD (see appendix D.8.2). This demonstrates that our findings are robust to using an alternative (hand-coded) measure of social conflict and shows that the results hold in African countries, where there are no concerns about changes in mobile standards (from CDMA to GSM) contaminating treatment assignment. Table A.13 reports results that confirm what we found using the GDELT data. (As a percentage of the baseline probability, these effects we find using the SCAD are actually larger.) Finally, the results are robust to changing the unit of observation to smaller $\left(1 \mathrm{~km}^{2}\right)$ or larger $\left(24 \mathrm{~km}^{2}\right)$ grid cells, as well as to using a sample of major cities (table D.7). In table A.15, we also show that cell phones per capita are associated with a higher probability of protest and number of protests at the country level.

These results line up with recent findings from Manacorda and Tesei (2016), who show that cell coverage increases protest activity in Africa during economic recessions. However, our argument and analysis differ in several ways. First, we do not restrict attention to Africa (except when analyzing the SCAD data). The motivating anecdotes from Hong Kong, Iran, or Turkey suggest a more global relationship. Second, we employ a much finer unit of analysis; the PRIO grid cells they use are at least $55 \mathrm{~km}^{2}$, roughly 85 times larger than our units. Our cell fixed effects absorb timeinvariant characteristics for units roughly the size of a town; their cells, by contrast, are twice the size of the median US county. Third, given concerns about duplicate reporting in GDELT (which could be related to treatment), we employ a binary measure rather than relying on the reported counts. Finally, although the SCAD data indicates that roughly a quarter of all protests in Africa are repressed (Christensen 2017), they omit any discussion or analysis of repression.

\subsection{Cell Coverage and Repression}

We find that the effect of cell phone access on the probability of protest is greater where gaining access to the network connects a locality to a larger proportion of the citizenry. This is consistent with our second mechanism: governments should be less inclined to repress a protest if they know 
that protesters can rapidly share images of police brutality with a large audience of their fellow citizens. Anticipating less repression, protesters are then more willing to demonstrate. In this section we look for more direct evidence that the use of repression declines in areas that have received coverage.

The analysis in this section requires a few additional caveats. First, we are limited to the SCAD, which only includes African countries (with populations over one million) and does not contain information on social conflict beyond 2012. This lops off a large non-random chunk of our sample. Second, and perhaps more importantly, we only observe repression that occurs in response to protests. If no protest occurs in a grid cell-year, then (in this data) the government never has an opportunity to use repression, which induces the selection problem described in section 3.2. By removing observations where no protest takes place in the recent past (between 2000 and 2012 or the year of treatment, whichever comes first), we can obtain an estimate of a lower bound of the effect of coverage on repression (see section $\mathrm{C}$ for the logic behind this subgroup analysis). That is, if our formal model correctly describes the effect of cell phone coverage on repression decisions, our estimates understate the true reduction in repression.

Table 5: Summary Statistics: Coverage Expansion and Repression; SCAD

\begin{tabular}{lccccc}
\hline \hline Statistic & $\mathrm{N}$ & Mean & St. Dev. & Min & Max \\
\hline $\mathbb{1}$ (Repressed) & 1,976 & 0.0142 & 0.1182 & 0 & 1 \\
$\mathbb{1}$ (Covered) & 1,976 & 0.0693 & 0.2541 & 0 & 1 \\
$\mathrm{~m}$ & 1,976 & 0.4149 & 0.3011 & 0.0018 & 0.9978 \\
\hline
\end{tabular}

We start by presenting these results graphically in figure 4: while the probability of repression appears to follow parallel trends in treatment and control areas prior to the expansion of coverage, the likelihood of repression falls considerably in treated areas. This decrease is especially striking given the increasing probability of repression observed in uncovered areas. The results from equation 3 are presented in table 6. Our difference-in-differences estimates suggest that the probability 
Figure 4: $\operatorname{Pr}$ (Repress) Pre-/Post-Coverage Decline in repression only after coverage.

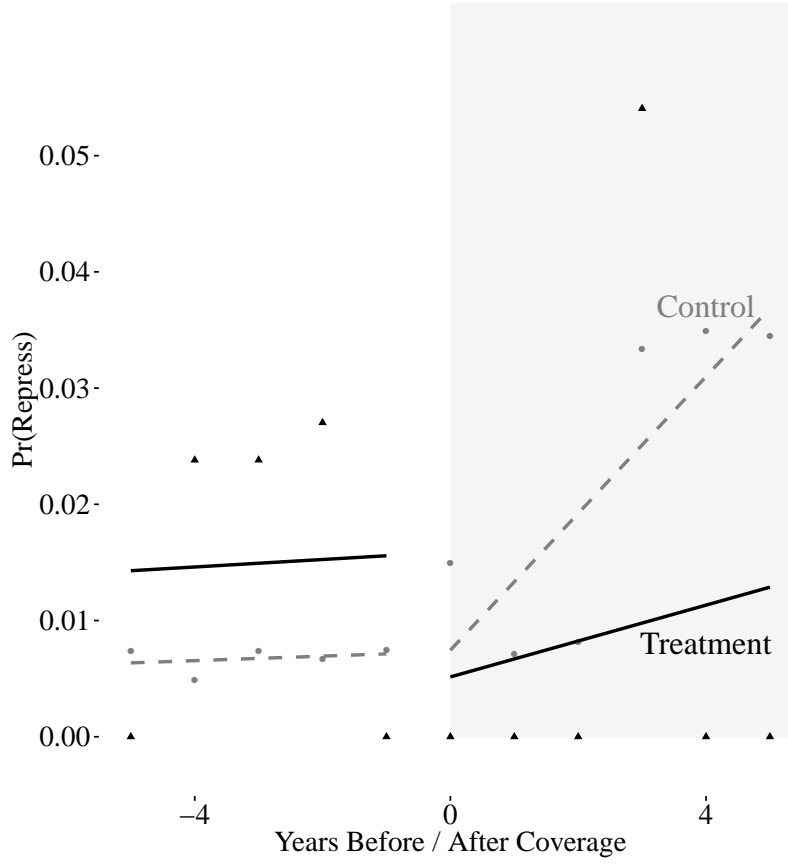

The figure plots the probability of repression in the years before and after coverage. The table includes linear probability models, as specified in equation 3. Data on repression comes from SCAD, and information on cell phone coverage is taken from the Collins Mobile Coverage Explorer database. Per section C, the sample is grid cells that experienced a protest between 2000-2012 or prior to treatment (whichever comes first).

of repression is considerably lower after grid cells gain access to a cell phone network. ${ }^{19}$ We regard these results as suggestive of the second mechanism highlighted by the model, though they are not statistically significant ( $t \approx 1.3$, for the first two models). When we interact coverage with the proportion of the population covered by the network, the coefficient is negative, as expected, but also very imprecisely estimated.

\subsection{Cell Phone Coverage and Reporting Bias}

One concern about the data underlying these results is that cell phones could enable journalists to learn about and report on protests. As a result, protests in areas with cell networks may

\footnotetext{
${ }^{19}$ Including logged luminosity has no effect on these point estimates.
} 
receive more coverage and, thus, be more likely to appear in our event datasets, which are based on news reports. In a recent article, Weidmann $(2015,6-7)$ provides evidence that cell phone coverage increases the probability that international news outlets report armed conflicts in Afghanistan.

We take a number of steps to ameliorate concerns that such reporting bias could drive the effects we detect. Two features of our empirical design address potential reporting bias. First, unlike cross-sectional studies, we control for all features of grid cells that do not vary between 2007 and 2014. We are not worried then about reporting biases that are driven by geography, distance to a major city or border, or the language spoken in a particular place. Second, we include a timevarying measure of development, luminosity. This addresses the concern that as areas develop, they are more likely to garner reporters' attention.

We go further and look at whether the average number of articles or sources reporting on protests increase when locations transition into cell phone coverage. That is, we run our same difference-in-differences (equation 1) but use the average number of articles or sources per protest (from GDELT) as the dependent variable. Our estimates are negative and small relative to the mean. These results suggest that the intensity of media coverage did not meaningfully change when areas transitioned into cell phone coverage, providing more direct evidence that reporting bias is not in play. The number of observations drops in these regressions, as these only include cell-years that have protests.

Table 7: Summary Statistics: Media Coverage; GDELT Data

\begin{tabular}{lccccc}
\hline \hline Statistic & $\mathrm{N}$ & Mean & St. Dev. & Min & Max \\
\hline Mean(Articles) & 17,158 & 6.023 & 7.767 & 1.000 & 531.000 \\
Mean(Sources) & 17,158 & 1.211 & 1.145 & 1.000 & 57.000 \\
$\mathbb{1}$ (Covered) & 17,158 & 0.532 & 0.499 & 0 & 1 \\
Log Luminosity $_{t-1}$ & 17,158 & 1.549 & 1.473 & 0.000 & 4.159 \\
\hline
\end{tabular}

Finally, we pursue a bounding approach and find that reporting bias would need to be large 
Table 8: Coverage Expansion and Media Coverage; GDELT Data Cell phone coverage does not increase reporting on protests.

\begin{tabular}{lcccc}
\hline \hline & \multicolumn{4}{c}{ Dependent variable: } \\
\cline { 2 - 5 } & Mean(Articles/Protest) & Mean(Sources/Protest) \\
& $(1)$ & $(2)$ & $(3)$ & $(4)$ \\
\hline $\mathbb{1}$ (Covered) & -0.101 & -0.102 & -0.019 & -0.021 \\
& $(0.329)$ & $(0.329)$ & $(0.047)$ & $(0.047)$ \\
& & & & \\
Log Luminosity $t-1$ & & 0.053 & 0.115 \\
& & $(0.495)$ & $(0.110)$ \\
\hline Cell FEs & \multicolumn{5}{c}{10,614} & 10,614 \\
Year FEs & 10,614 & 10,614 & 6 \\
Observations & 6 & 6 & 6 & 17,158 \\
\hline
\end{tabular}

Note:

Robust std. errors clustered on grid cell.

Notes: columns 1-4: OLS regressions, where the dependent variable is the average number of news articles or news sources reporting on each protest. The unit is the grid cell-year. This analysis uses the same sample of grid cells as table 3. However, the outcome variable can not be measured in grid cell-years that do not experience protest; hence, the reduced sample. See table 3 for other data sources.

to generate our effects (Hollenbach and Pierskalla (2017) and Gallop and Weschle (2017) employ a similar approach). This bounding exercise (summarized by figure A.6) indicates the the probability of reporting in treated and untreated areas would have to differ by more than 15 percentage points to explain away our effects. This seems unreasonable given that Weidmann's estimates place this bias at around six percentage points in Afghanistan - a war zone where reporting challenges are extreme.

Any data set built on media or third-party reports suffers some degree of underreporting. However, we do not find evidence that cell phone coverage increases the resources devoted to reporting on protests. Moreover, we find that the reporting bias would have to more than double what Weidmann (2015) finds to completely account for our effects. Given these two pieces of evidence, we feel confident that our results are not explained by increased media attention post-treatment. 


\section{Conclusion}

This paper addresses an ongoing debate about whether and why cell phones affect protest activity around the world. We make two advances. The first is theoretical: we present an argument for how cell phones both reduce coordination costs and deter repression. Our second contribution is empirical: we find that gaining access to the cell phone network increases the probability of protest by more than half the baseline probability of protest. Furthermore, this effect is larger in cases where a large proportion of citizens already have access to the network - a finding consistent with our argument that cell phones increase the risk of escalation and, thus, deter repression. We also find suggestive evidence that the probability of repression declines after an area gains access to the cell network, though these estimates are imprecise and plausibly a lower bound of the true effect.

More broadly, we address questions about how citizens coordinate to assert their demands, and when such mobilization is tolerated or met with brutal repression. Cell phones are simply a technology - albeit an important one - that enables individuals to quickly disseminate information both about their political intentions and any government response. While nearly every country constitutionally recognizes citizens' rights to freely associate, many fewer honor this right in practice (Christensen and Weinstein 2013). This paper provides a model, supported by empirical evidence, for thinking about when governments allow citizens to engage in public dissent - not because of the undeniable normative appeal of free association but because cracking down is counter-productive. 


\section{References}

ABC News. 2011. "Social Media Fuels Protests in Iran, Bahrain, and Yemen." $A B C$ News, February 15.

Aumann, Robert J. 1976. “Agreeing to Disagree.” The Annals of Statistics 4:1236-1239.

Autor, David H. 2003. “Outsourcing at Will: The Contribution of Unjust Dismissal Doctrine to the Growth of Employment Outsourcing." Journal of Labor Economics 21(1):1-42.

Balbus, Isaac D. 1973. The Dialectics of Legal Repression. Russell Sage Foundation.

Banks, Arthur S and Kenneth A Wilson. 2014. “Cross-National Time-Series Data Archive.” Databanks International.

Boschee, Elizabeth, Jennifer Lautenschlager, Sean O’Brien, Steve Shellman, James Starz and Michael Ward. 2015. "ICEWS Coded Event Data." Harvard Dataverse.

Caren, Neal and Sara Gaby. 2011. "Occupy Online: Facebook and the Spread of Occupy Wall Street." Working Paper.

URL: $h t$ tps://ssrn.com/abstract $=1943168$

Chen, Xi and William D Nordhaus. 2011. "Using luminosity data as a proxy for economic statistics." Proceedings of the National Academy of Sciences 108(21):8589-8594.

Christensen, Darin. 2017. “The Geography of Repression in Africa." Journal of Conflict Resolution .

Christensen, Darin and Jeremy M Weinstein. 2013. "Defunding Dissent." Journal of Democracy 24(2):77-91.

Chwe, Michael Suk-Young. 2001. Rational Ritual: Culture, Coordination, and Common Knowledge. Princeton University Press.

Davenport, Christian. 2007. “State Repression and Political Order" Annual Review of Political Science 10:1-23.

Doll, Christopher N H, Jan-Peter Muller and Jeremy G Morley. 2006. "Mapping regional economic activity from night-time light satellite imagery." Ecological Economics 57(1):75-92. 
Dorsey, Steve. 2013. “Turkey’s Social Media And Smartphones Key To ‘Occupy Gezi’ Protests.” Huffington Post, June 9.

Enikolopov, Ruben, Alexey Makarin and Maria Petrova. 2016. "Social Media and Protest Participation: Evidence from Russia." Working Paper .

Fischer, Claude S. 2013. "New media and old manifestations." The Berkeley Blog, June 27.

URL: $h t t p: / / b l o g s . b e r k e l e y . e d u / 2013 / 06 / 27 / n e w-m e d i a-a n d-o l d-m a n i f e s t a t i o n s /$

Gallop, Max B and Simon Weschle. 2017. "Assessing the Impact of Non-Random Measurement Error on Inference: A Sensitivity Analysis Approach." Political Science Research and Methods .

Garfias, Francisco, Beatriz Magaloni, Ruth Kricheli and Yair Livne. 2016. “Taking to the Streets: Theory and Evidence on Protests under Repressive Regimes." Working Paper .

Goldstone, Jack A and Charles Tilly. 2009. Threat (and Opportunity): Popular Action and State Response in the Dynamics of Contentious Action. In Silence and Voice in the Study of Contentious Politics, ed. Ronald R Aminzade, Jack A Goldstone, Doug McAdam, Elizabeth J Perry, William H Sewell Jr, Sidney Tarrow and Charles Tilley. Cambridge: Cambridge University Press pp. 179-194. Hafner-Burton, Emilie M. 2005. "Trading Human Rights: How Preferential Trade Agreements Influence Government Repression." International Organization 59(03):593-629.

Hamburger, Ellis. 2014. “Facebook's new stats: 1.32 billion users, 30 percent only use it on their phone." The Verge, July 23.

Hassanpour, Navid. 2014. “Media Disruption and Revolutionary Unrest: Evidence from Mubarak's Quasi-Experiment." Political Communication 31(1):1-24.

Hendrix, Cullen S and Idean Salehyan. 2012. "SCAD 3.0 Codebook.”.

Hendrix, Cullen and Wendy Wong. 2013. "When Is the Pen Truly Mighty? Regime Type and the Efficacy of Naming and Shaming in Curbing Human Rights Abuses." British Journal of Political Science 43(3):651-672.

Hollenbach, Florian M and Jan H Pierskalla. 2017. "A Re-Assessment of Reporting Bias in EventBased Violence Data with Respect to Cell Phone Coverage." Research \& Politics 4(3). 
Howard, Philip N, Aiden Duffy, Deen Freelon, Muzammil Hussain, Will Mari and Marwa Mazaid. 2011. “Opening Closed Regimes.” Working Paper.

URL: $h t t p: / / g o o . g l / P q R P O e$

Kelly Garrett, R. 2006. "Protest in an Information Society: a review of literature on social movements and new ICTs." Information, Communication \& Society 9(2):202-224.

Kern, Holger L and Jens Hainmueller. 2009. “Opium for the Masses: How Foreign Media Can Stabilize Authoritarian Regimes.” Political Analysis 17(4):377-399.

Khamis, Sahar and Katherine Vaughn. 2011. "Cyberactivism in the Egyptian Revolution: How Civic Engagement and Citizen Journalism Tilted the Balance ." Arab Media and Society (14).

King, Gary, Jennifer Pan and Margaret E Roberts. 2013. "How Censorship in China Allows Government Criticism but Silences Collective Expression." American Political Science Review 107(02):326-343.

Kuran, T. 1991. "Now out of never: The element of surprise in the East European revolution of 1989." World Politics 44(01):7-48.

Lawrence, Adria. 2017. “Repression and Activism among the Arab Spring’s First Movers: Morocco’s (Almost) Revolutionaries." British Journal of Political Science 47(3):699-718.

Leetaru, Kalev and Philip A Schrodt. 2013. "GDELT: Global Data on Events, Location and Tone, 1979-2012.”.

URL: $h t t p: / / d a t a . g d e l t p r o j e c t . o r g / d o c u m e n t a t i o n / I S A .2013 . G D E L T . p d f$

Leung, Ben. 2014. “Police Brutality Inflames Hong Kong.” The Daily Beast, October 15.

Lichbach, Mark. 1984. "An economic theory of governability: Choosing policy and optimizing performance." Public Choice 44(2):307-337.

Little, Andrew T. 2015. “Communication Technology and Protest.” The Journal of Politics 78(1):152166.

Manacorda, Marco and Andrea Tesei. 2016. "Liberation Technology: Mobile Phones and Political Mobilization in Africa." Working Paper pp. 1-73. 
Marshall, Monty, Keith Jaggers and Ted Gurr. 2012. "Polity IV Project: Political Regime Characteristics and Transitions, 1800-2010.”

Oak Ridge National Laboratory. 2012. "LandScan.” Oak Ridge National Laboratory.

Opp, Karl-Dieter and Wolfgang Roehl. 1990. "Repression, Micromoblization, and Political Protest.” Social Forces 69(2):521-547.

Patel, David S. 2007. "Islam, Information, and Social Order: The Strategic Role of Religion in Muslim Societies." PhD Dissertation, Department of Political Science, Stanford University, Stanford, CA.

Pierskalla, Jan H. 2010. "Protest, Deterrence, and Escalation: The Strategic Calculus of Government Repression.” Journal of Conflict Resolution 54(1):117-145.

Pierskalla, Jan H and Florian M Hollenbach. 2013. "Technology and Collective Action: The Effect of Cell Phone Coverage on Political Violence in Africa." American Political Science Review 107(2):207-224.

Preston, Jennifer. 2011. “Social Media Gives Wall Street Protests a Global Reach.” The New York Times, October 15.

Raytheon BBN Technologies. 2015. BBN ACCENT Event Coding Evaluation. Technical report.

Rubinstein, Ariel. 1989. “The Electronic Mail Game: Strategic Behavior Under ”Almost Common Knowledge". The American Economic Review 79(3):385-391.

Schrodt, Philip A and Omur Yilmaz. 2007. "CAMEO Conflict and Mediation Event Observations Codebook.".

Selian, Audrey. 2001. “3G Mobile Licensing Policy: From GSM to IMT-2000 - A Comparative Analysis." Proceedings from the $3 G$ Licensing Workshop .

Shapiro, Jacob N and David A Siegel. 2015. "Coordination and Security: How mobile communications affect insurgency." Journal of Peace Research 53(3):312-322.

Shapiro, Jacob N and Nils Weidmann. 2015. "Is the Phone Mightier than the Sword? Cell Phones and Insurgent Violence in Iraq.” International Organization 69(2):247-274.

Siegel, David A. 2011. "When Does Repression Work? Collective Action in Social Networks." The 
Journal of Politics 73(04):993-1010.

Steinart-Threlkeld, Zachary C. 2014. "Machine Coded Events Data and Hand-Coded Data." Political Violence at a Glance .

Tufekci, Zeynep and Christopher Wilson. 2012. "Social Media and the Decision to Participate in Political Protest: Observations From Tahrir Square." Journal of Communication 62(2):363-379.

Walter, Barbara F. 2006. "Building reputation: Why governments fight some separatists but not others." American Journal of Political Science 50(2):313-330.

Ward, Michael D, Andreas Berger, Josh Cutler, Matthew Dickenson, Cassy Dorff and Ben Radford. 2013. "Comparing GDELT and ICEWS Event Data." Analysis 21:267-297.

Warren, T Camber. 2015. "Explosive connections? Mass media, social media, and the geography of collective violence in African states." Journal of Peace Research 52(3):297-311.

Weidmann, Nils. 2015. "A Closer Look at Reporting Bias in Conflict Event Data." American Journal of Political Science pp. 1-13.

Weidmann, Nils B and Sebastian Shutte. 2017. "Using Night Light Emissions for the Prediction of Local Wealth." Journal of Peace Research 54(2):125-140.

Weyland, Kurt. 2012. "The Arab Spring: Why the Surprising Similarities with the Revolutionary Wave of 1848?" Perspectives on Politics 10(04):917-934.

Whitten-Woodring, Jenifer and Douglas A Van Belle. 2014. Historical Guide to World Media Freedom: A Country-by-Country Analysis. Sage/CQ Press.

Yanagizawa-Drott, David. 2014. "Propaganda and Conflict: Evidence from the Rwandan Genocide." The Quarterly Journal of Economics 129(4):1947-1994. 